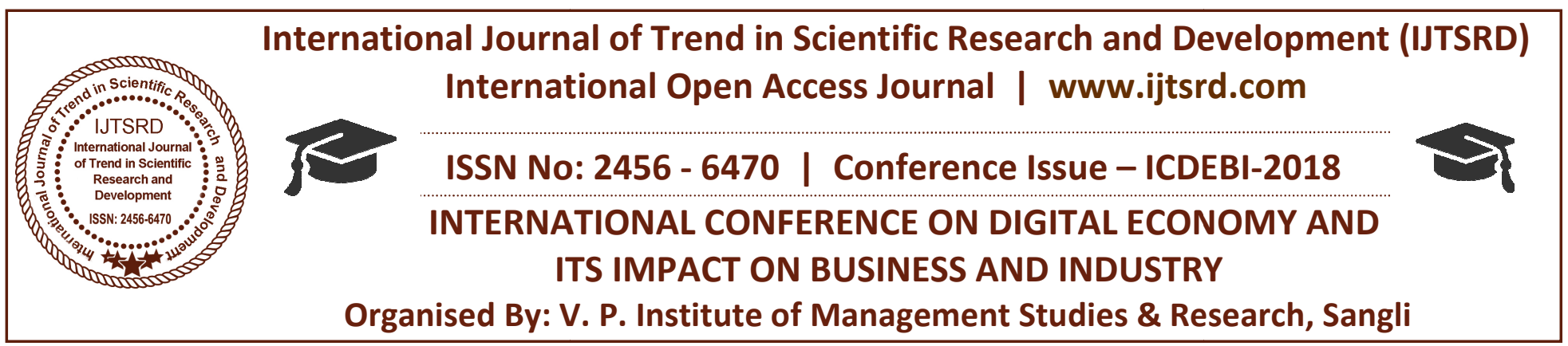

\title{
Digitalization in Education Sector
}

\author{
Dr. Satish Marathe \\ Associate Professor, Tilak Maharashtra University, Pune, Maharashtra, India
}

\begin{abstract}
In today's world, digitalization has been a game changer in one of the most important sectorsEducation. It has been effectively used as a prominent technique in the whole gamut of education sector. It has blurred the boundaries of physical distance, as well as, has embedded more scientific ways to impart knowledge from tutors to the students. Digitalization would also mean huge savings in the resources (infrastructure of seating capacities, printing of books, notes, papers etc.)
\end{abstract}

Primary objective of the study is to highlight evolving of digitalization\& its economic impact on the education sector. Digitalization of education assumes to include two inseparable components - a) classroom learning concepts and b) online learning methods. The paper also describes various terms and types of digitalization. It discusses advantages and disadvantages of online methods of learning.

This paper also tries to differentiate between 'Oldschool' techniques and 'Digitalized' techniques in education. While there are obviously seen advantages of Digitalized education sector, there are still merits in certain aspects of 'Old-school' education.

The nature of the study is semi empirical. Various theory concepts, experiential learning and data points from external sources have been used while arriving at recommendations and views expressed in this paper.

\section{INTRODUCTION}

Digitization is the process of converting information in to a digital format. It has many advantages and a few disadvantages as well. It combines concepts of classroom learning and online learning methods.
Digitization is very useful not only in education but also in sectors like banking, finance, insurance, marketing, shopping, heavy industries, travel and tourism, hotel industry and in the field of medicine. Within education sector, it has different applications like online courses, online examinations, digital textbooks, animations, and administrative activities.

A differently coined term 'Digitalization' is the application of electronic / digital techniques to existing manual and paper-based process for better revenue generation and improved business models enabled by the digitization of information.

The difference between digitization and digitalization is very important. While digitization is process of converting information/data in to digital format; digitalization is the use of digital technologies to change a business model and provide new revenue producing opportunities.

We are in the $21^{\text {st }}$ century where technology is changing at a rapid pace. Smartphone, laptops, and tablets are not foreign terms to common people anymore. And with fast speed data connectivity made available across the country, adoption of digitalization has catapulted to a new high.

When we consider education sector, it's dynamics are changing by every passing day. Along with the methods, mentality of students is also changing. They are extremely curious today and are not restricted with textbooks that were traditionally available in the book stores or libraries. Their methods of learning are changing every day. Learning through YouTube, online portals, apps is a common thing now. Their 
curiosity is vast and cannot be fulfilled with conventional educational systems.

Traditional educational system lacks these advancements and hence we are compelled to use digitalization in our educational system.

Online courses, online examinations, digital textbooks, animations, and administrative activities are known and popular ways digitalization in education system. There are various adaptations in the education sector such as learning through phonics that are fun, interesting and easy to understand. This technique is primarily used for kids' learning wherein sound, pictures, and stories are woven together and presented to kids in an electronic form.

\section{Education system - then and now}

In the previous era, knowledge transfer was strictly was through the lessons given by teachers to his pupils. This method ensured that not only theoretical knowledge was getting imparted, but also the real-life experiences were amalgamated into it so that pupils could learn the nuances of the lessons.

Although Digitalization has changed the education sector dramatically, the traditional way of GuruShishya method of imparting knowledge is irreplaceable. It cannot diminish the importance of old education system. Digitalization in education has led to misconception that the relevance of the teacher would gradually fade away in an era of e-learning.

The institution of teacher remains a strong pillar of the education system.

Teacher plays an important role in today's education system too and guides his pupils to identify places where his students can apply the knowledge and also the likely pitfalls. There is no doubt that students will be felt deprived if they are not learning in a digitalized world today, just that pivotal role of teacher needs to be understood by all elements of this sector.

Below are the key observations for traditional or old education system:

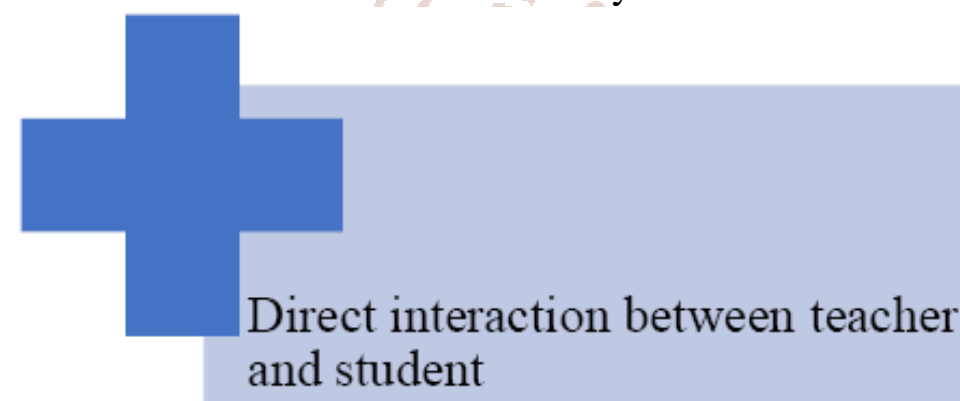

Stress on important part of the syllabus

Reading on related areas which are not part of the syllabus

Extra preparations for the student with low understanding level

Guru- Shishya parampara system allowed shishya to observe, experience and learn from his /her guru $24 \times 7$
Lack of dynamism

Learning is limited to syllabus, teacher and subject

It makes student exam oriented

It does not equip student for practical application of knowledge It is not cost effective. Traditional education has become very costly.

Resources like books/teachers have limitations. If books/teachers are inadequate learning will stop

While for online education, below are the observations w.r.t. advantages and disadvantages: 


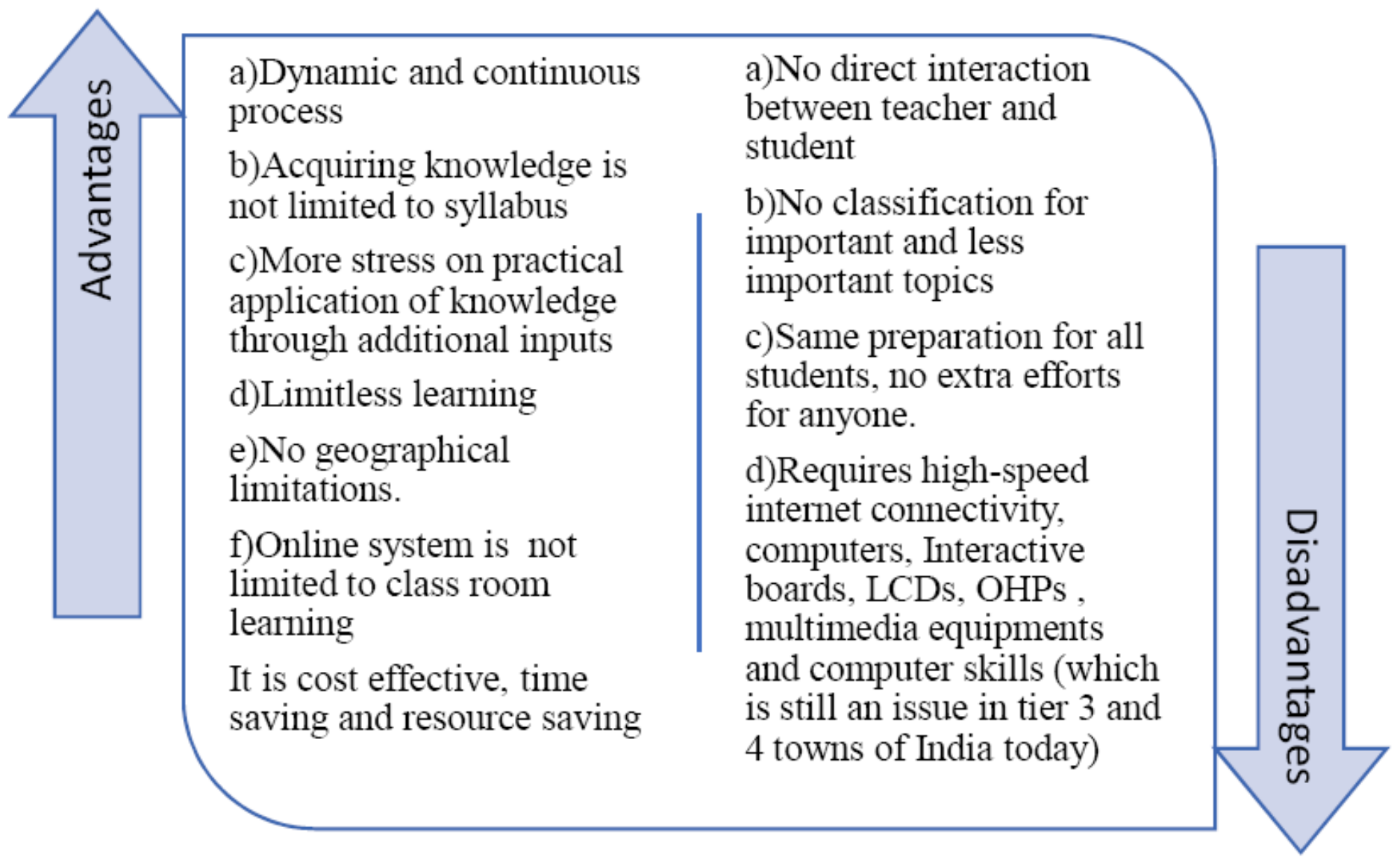

\section{Expanse of the online education}

Today in India, traditional and online education systems are existing in parallel. Online system is in transitional phase actually. We are not yet completely detached from old learning system and at the same time, we are slowly and gradually accepting online systems.

Entrance examsare online / digitalized but latter, the education imparted in classroom, is through traditional way. While online methods can accurately evaluate answers of multiple choice questions, they cannot really evaluate the subjective answers easily. Hence, it is partly accepted for higher education but primary and high school education still uses old system. Teaching and examinations still happen with old system. Results are declared with online systems. We are in a phase of preparing our teachers and students for online education system. Even application of online system for administrative purposes is in mixed state.

The staff and student lack the required skills for complete application. All types of fess are still paid in schools and colleges. Online payment system is not fully accepted. Present education system is combination of an old system and new system.
Application of online techniques in various parts of education

The new phase of learning has begun and involves various advanced techniques and methods like:

1. Online self-paced or timed courses

2. Online examinations

3. Digital textbooks

4. Animation

5. Videos and films and PowerPoint presentations

6. Use of multimedia equipment like interactive boards, LCDs, Laptop and advanced projectors.

Brief description is given below for important technologies in use.

1. Online courses - They are used to learn a new language or get trained in some specific course, or even to learn through distance learning. Online courses are developed by experts who have unmatched proficiency in their specific field and can give you the experience of real-time learning by designing their own online course.

2. Online examinations - Examination process is convenient for both teachers and students.

3. Digital textbooks - Digital textbooks provide an interactive interface in which the students have access to multimedia content such as videos, interactive presentations, and hyperlinks. 
4. Learning through animations - This is typically used for educating children between two five years old. Learning through pictures, diagrams, through colors is more effective.
5. Videos and films and power point presentations are used for student of any age group. Management films, motivational films, are examples of this method.

\section{SWOT - online education in India}

SWOT analysis for online education in India is tabled below:

\section{Strenoths}

- Time and location independent

- Impartiality

-Exposure to Global standard of

education

-Access to all irrespective of

circumstances
Opportunities:

-Enrolment of more number of

students in a session

-Graduation / higher studies

without disturbing the Work-life

Balance

- Time saving and cost efficient

Education to all categories of pupils

Access to variety of training

materials, joumals, books.

library, webinars

\section{Scope and Limitations}

If we were to define scope of Digitalization in India today, it is expected to pervade almost each and every area of education. It will be wide spread; right from primary education to higher studies and onto research field as well. It will also be pervasive in all other fields like health, transport, travel tourism, insurance, banking, finance etc. It will be consumer centric and will be made extremely convenient. Though personal or human interaction would not be available, but accuracy and repeatability will be enhanced through automation capabilities embedded within.

\section{Conclusion \& future of online education}

Based on the figures made available in KPMG's report and Quora, it is evident that future of digital market and online education system in India is extremely bright. There is huge scope for implementation. Digitalization in education, banking, insurance, financial services, agriculture, and other

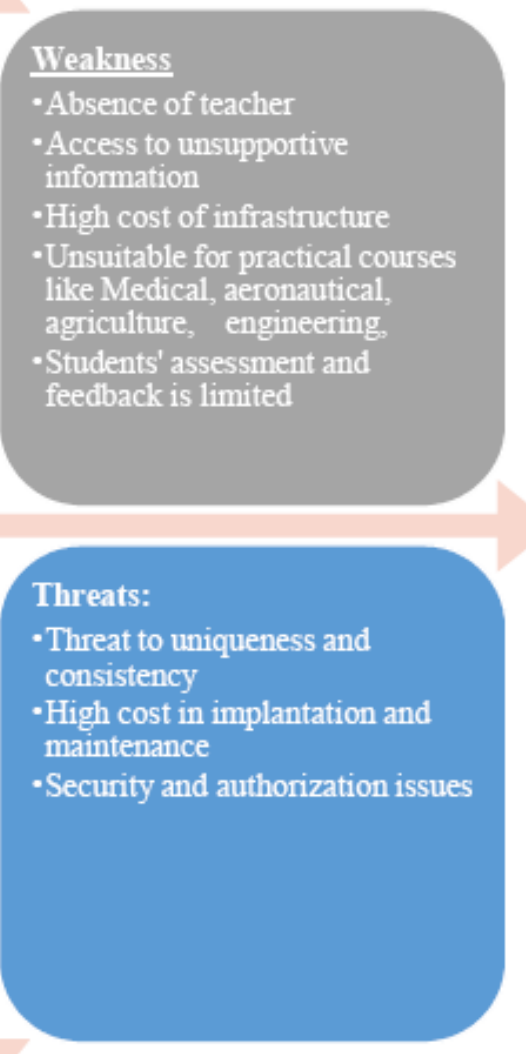

sectors of economy are going to open many opportunities for service providers.

These figures, give us an overview of the growth potential which India has for online education.

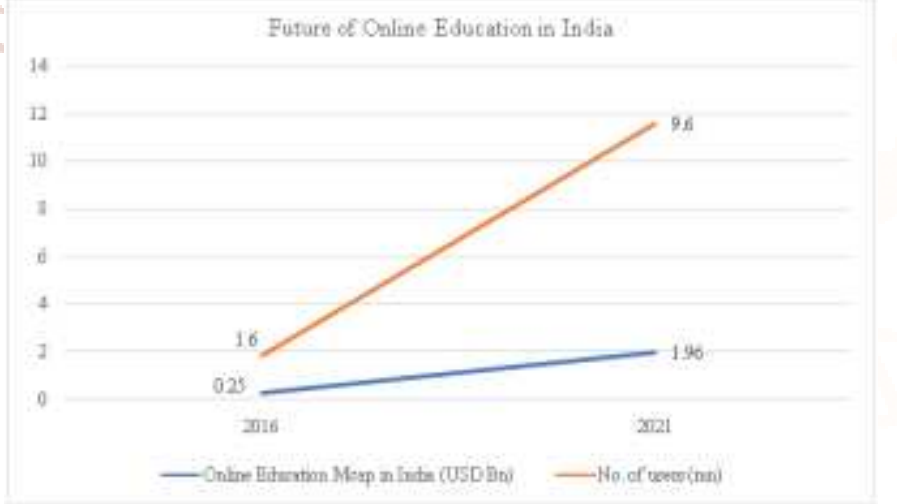

Increase in number of users of online education systems, increasing cost of traditional education, increase in number of internet users, estimated 
increase in number of open learnings and distant learning courses by 2021 and percentage of ambitious young population with low income. Population between age group 15 to 25 is target market for online education.

Following key conclusions can be drawn:

Online education market in India is set to increase at an astonishing rate i.e. CAGR of $52 \%$, from 2016 to 2021

$>$ Number of users in online education to grow $6 \mathrm{x}$ from 2016 to 2021. This is in-line with internet penetration rate in India which is $31 \%$ today with almost $409 \mathrm{Mn}$ internet users, and nearly 735 Million new users are predicted by 2021.

Also, the cost of traditional education from 2008 to 2014 has risen by $175 \%$, hence online education is a low-cost alternative to traditional education.

And, open learnings and distant learning courses are expected to grow to $10 \mathrm{Mn}$ by 2021 .

Nearly $46 \%$ population is between $15-40$ age group. The young population with high aspirations but lower income is good target market for online education. The acceptability of online channel is high in younger demographic.

Report also indicates that people trying to provide generic online education via non-personalized games and animations and standard courses would struggle to exist in near future looking at the trend and platforms that provide personalized learning experience will grow. (Source: -www.quora.com)

Digitalization means advance technology and more usage of electronic media, which will improve country's GDP and bring more revenue. If we follow trend of USA/UK, where digitalization is implemented twenty years earlier than India, we are sure that digitalization will make Indian economy stronger with strong GDP and good growth rate.

Presently it is e-learning and test preparation which are leading the market, but in future years to come, gamification (using game rules to non-game situation and making learning experience more enjoyable and fun giving, which can retain the students interest in learning.) and application of technologies like Virtual Reality and Artificial Intelligence is going to make an impact in the pedagogy.
Digital technologies given below will impact economy of the country and improve the performance of online education. It will also increase market depth and will bring more revenue to the country.

1. Big Data: Users create digital footprints via interaction of the platform, which are captured by system to map their profiles and suggest them proper course and material.

2. Data Analytics: Mapping academic/professional background and drive purchase behaviour.

3. Wearable devices: New mode of content consumption.

4. Virtual Reality: Virtual labs can be setup to perform experiments.

5. Machine Learning: A detailed feedback given to each student with level of accuracy, grasping power, time spent on different concepts, historical performance.

6. Artificial Intelligence: Providing profile based customized course suggestions to prospective students. Help students to make informed choice on course content, type of course, type of evaluation and course duration.

And from the Business Model point of view, online players may adopt hybrid channels to reach their customers. Like, online learning platforms may start engaging with the students through offline touch points- labs, group discussions, panel discussions, to bridge the gap with traditional modes of learning.

Digitalization has changed our education system undoubtedly, but we cannot say that it has diminished the value of our traditional classroom learning. It also cannot replace Guru-Shishya parampara (conventional student - teacher learning method) which was used in older days. During those days, students used go and stay with their Guru for ten to twelve years. This system was more profound in use for performing arts like singing, dancing, painting, drawing, etc.

In a nutshell, India has exciting opportunities in Edtech sector with rising young population, increasing internet penetration and acceptance of online learning as a cost-effective channel.

Following conclusions can be drawn at the end of this study on digitalization of education sector in India:

$>$ Digitalization in education system will be a big success in future (at least 50 years)

It will be beneficial to all stakeholders in education. Important among them are givers of 
educations (schools, colleges, universities,) and receivers of education i.e. Students.

$>$ It will improve efficiency of present education system.

$>$ It will be more precise and accurate.

$>$ It will reduce waiting time of student.

$>$ It will save on national resources.

$>$ Campuses of universities and colleges and schools may not exist and traditional classroom learning will be replaced by distance learning.

$>$ Present examination system will be replaced by online examination system.

$>$ Results will be declared immediately. No waiting.

$>$ Repeat examinations will happen quickly.

$>$ Payment of fees, admissions and registration for the course, examination form filling, giving examination, improvement in student performance, etc will be conducted online only

$>$ Physical movements of students from home to college/universities may not really be required. It will save on transportation cost.

$>$ Only disadvantage would be online or digitalized education will not give a personal touch.

\section{Recommendations}

1. Looking at the growth opportunities for online education, distance learning, and e-learning, sizable amount of provisions should be made in budget for education. At present less than $4 \%$ of GDP is provided for traditional education in central budget. Budget provision are Rs. 85,000 crores

2. Government must provide strong internet high speed connectivity to rural citizens. Budget indicates only 5 crores are provided for broad band access. This is turning factor for development for online education. Budget provisions for digital India in 2018-19 is Rs. 3073Crores.Global economy is changing to digital
economy.Rs.864is provided for promotion of digital econoy.Rs.4000will be spent on digital literacy programme. Rs.30crores will be spent on development of manpower development. Set up of 5lacs. Wi-Fi hotspots will provide broadband access to 5crores rural citizens (source: www.thehindu.com)

3. Training programme for teachers and students to adapt technology for online and distant learning.

\section{Citations and references}

1. KPMG in India \& Google report: Online Education in India : 2021, May 2017

2. Information on Quora: Scope of digitalization of education in India

3. Article published in Hindu: Article related to digitalization of education In India

4. https://www.scribd.com/doc/87780483/SWOTanalysis-of-Indian-Higher-Education

5. https://www.slideshare.net/imtiazlove/swot-onindian-education-industryppt

6. E-learning in India SWOT analysis. www.ijetmas.com/admin/resources/project/paper/f 201711051509883239.pdf

7. https://inc42.com/buzz/indian-online-educationedtech-market/

8. https://www.indiatoday.in/educationtoday/featurephilia/story/digitisationeducation-1045356-2017-09-18 (Digitalization making teachers life simple or more complicated)

9. https://www.entrepreneur.com/article/302680 (Five reasons for why digitization is must for education sector)

10. https://elearningindustry.com(Digitization of education in 21 st century) 